\title{
Open lung biopsy in patients with respiratory failure
}

\author{
Walid Abu Arab ${ }^{\mathrm{a}, \mathrm{b}, *}$, Marco Sirois $^{\mathrm{a}}$, Chantal Sirois ${ }^{\mathrm{a}}$ \\ ${ }^{a}$ Department of thoracic surgery, Faculty of Medicine and Health Sciences, University of Sherbrooke, Canada. \\ ${ }^{b}$ Department of cardiothoracic Surgery, Faculty of Medicine, University of Alexandria, Egypt.
}

\begin{abstract}
Open lung biopsy (OLB) is known as the gold standard for the definitive diagnosis of parenchymal lung diseases, whether they are acute or chronic and/or localized or diffused. It has high diagnostic yield over bronchoalveolar lavage and transbronchial needle biopsy. The use of OLB in non-intensive care unit (nonICU) patients is considered a relatively safe technique, but its use in critically ill patients and ICU patients is a subject of argument. Methods: This paper reviews the English literature to evaluate the role of OLB in critically ill patients to determine its safety and outcomes. Twenty-two, original, published articles were found in the literature. Analysis of each study was done regarding indication for OLB, post-OLB management, complications and outcome. In conclusion OLB is a potentially safe procedure that could help to establish a diagnosis in patients with diffuse lung disease and respiratory failure. It may lead to significant changes in therapy but also, it carrries the risk of complications. A large randomized study should be performed to determine the benefits, value, and outcomes of the employment of OLB in critically ill patients with undiagnosed respiratory failure.

Keywords: Open lung biopsy; mechanical ventilation; diffuse lung disease; bronchoalveolar lavage; transbronchial needle biopsy
\end{abstract}

\section{INTRODUCTION}

Open lung biopsy (OLB) is considered the gold standard method for definitive diagnosis of parenchymal lung diseases, whether they are acute or chronic and/ or localized or diffused ${ }^{[1-4]}$. Precise diagnosis helps to establish a specific therapy that may be lifesaving [5]. Although there are other different diagnostic methods that could be used, such as bronchoalveolar lavage (BAL) and transbronchial needle biopsy (TBB), the OLB is still considered the best tool to diagnose parenchymal lung disease ${ }^{[3,6]}$. A complete history, physical examination, chest radiography, and cultures will provide a reliable diagnosis in approximately $30 \%$ of patients ${ }^{[7,8]}$. The diagnostic yield of fiberoptic bronchoscopy investigations ranges from $38 \%$ to $85 \%$ according to the classification

*Corresponding author: Dr. Walid Abu Arab

Mailing address: Department of thoracic surgery, Faculty of Medicine and Health Sciences, University of Sherbrooke, 3001, 12th north avenue, Canada.

E-mail: walidabuarab@yahoo.com

Received: 24 February 2020 Accepted: 15 March 2020 of histological findings ${ }^{[7-9]}$. In contrast, the reported diagnostic yield of OLB ranges from $80 \%$ to $94 \%{ }^{[8,9]}$.

Nevertheless, despite recent advances in surgical techniques with the use of thoracoscopy, OLB is still considered an invasive procedure requiring general anesthesia and is associated with substantial morbidity and mortality ${ }^{[10-16]}$. The use of OLB in non-intensive care unit (ICU) patients is considered a relatively safe technique, but its use in critically ill patients and ICU patients is not well-studied and unclearly defined. The use of OLB is considered the last choice for diagnosis in mechanically ventilated patients and in those for whom empiric therapy for respiratory failure has been unsuccessful [17-19]. There is considerable controversy regarding the use of OLB in patients with respiratory failure and those on mechanical ventilation because of the potential high morbidity and mortality associated with its use [20,21]. While the role of OLB has become well-established in the diagnosis of interstitial lung disease ${ }^{[18]}$, its utility and safety are more controversial in critically ill patients. Proponents of OLB argue that solid diagnosis of underlying etiology can be helpful in determination of the best course of treatment ${ }^{[22]}$. Moreover, the risk of 
Table 1. Summary of the original published studies.

\begin{tabular}{llllll}
\hline No. & Authors & Journal & Year & Country & No. of Patients \\
\hline 1 & Nelems et al.[5] & Ann Thorac Surg & 1976 & Canada & 28 \\
2 & Warner et al.[40] & Am Rev Respir Dis & 1988 & USA & 80 \\
3 & Wagner et al.[2] & Am J Surg & 1992 & USA & 12 \\
4 & Canver et al.[46] & J Cardiovasc Surg & 1994 & USA & 27 \\
5 & Lachapelle et al.[44] & Can J Surg & 1995 & Canada & 31 \\
6 & Hughes et al.[47] & Can Respir J & 1997 & Canada & 27 \\
7 & Papazian et al.[49] & Anesthesiology & 1998 & France & 36 \\
8 & Kramer et al.[57] & Ann Thorac Surg & 1998 & Israel & 103 \\
9 & Flabouris et al.[8] & Chest & 1999 & Australia & 24 \\
10 & Chuang et al.[45] & J intensive care Med & 2003 & Taiwan & 17 \\
11 & Patel et al.[23] & Chest & 2004 & USA & 57 \\
12 & Soh et al.[50] & J Formos Med Assoc & 2005 & Taiwan & 32 \\
13 & Monteiro et al.[52] & Rev Port Pneumol & 2005 & Brazil & 24 \\
14 & Kao et al.[43] & Crit Care & 2006 & Taiwan & 41 \\
15 & Barbas et al.[38] & J Bras Pneumol & 2006 & Brazil & 12 \\
16 & Cho et al.[20] & Ann Thorac Surg & 2006 & USA & 53 \\
17 & Arabi et al.[39] & Med Sci Monit & 2007 & KSA & 14 \\
18 & Lim et al.[4] & Crit Care & 2007 & South Korea & 36 \\
19 & Papazian et al.[59] & Crit care Med & 2007 & France & 100 \\
20 & Baumann et al.[24] & Surgery & 2008 & Germany & 27 \\
21 & Charbonney et al.[51] & J crit care & 2009 & Switzerland & 19 \\
22 & Melo et al.[41] & Rev Port Pneumol & 2009 & Portugal & 19 \\
\hline
\end{tabular}

complications from biopsy is low if adequate precautions are undertaken ${ }^{[23]}$. In contrast, opponents of OLB believe that defining the underlying mechanism of injury is largely academic and will not affect the treatment of those patients because of the lack of specific therapies for underlying etiologies of Adult Respiratory Distress Syndrome (ARDS) and respiratory failure due to infiltrative lung diseases ${ }^{[17]}$.

This paper reviews the literature to evaluate the role of OLB in critically ill patients to determine its safety and outcomes. Twenty-two large, original, published articles were found in the literature. Table 1 summarizes the essential data for each study.

\section{DIAGNOSTIC INSTRUMENTS IN RESPIRA- TORY FAILURE}

Different diagnostic instruments are available for diagnosing the causes of respiratory failure of unknown origin associated with pulmonary infiltrates. Clinical, laboratory, and serologic data can help to reduce the number of possible differential diagnoses. Chest $\mathrm{x}$-rays and Computed Tomography of the Chest (CT- Chest) is useful for detecting complications of mechanical ventilation, such as atelectasis or pneumothorax ${ }^{[24]}$. Additionally, CT chest scans help to determine biopsy location, especially in nodular lesions or non-diffuse lesions ${ }^{[24]}$. However, regarding the underlying pathology, these tests have a limited informative role ${ }^{[25,26]}$.
BAL samples and the use of a bronchoscopic protected specimen brush are reliable for identifying both the quality and quantity of bacterial pneumonia microorganisms present in lung segments ${ }^{[27]}$. However, positive BAL results for infection may be difficult to interpret. Identification of Candida species in BAL represents a diagnostic difficulty because it is difficult to differentiate colonization from infection ${ }^{[28]}$. Moreover, identification of Cytomegalovirus in BAL fluid may indicate infection

Table 2. Percentage of specific diagnoses and alterations in therapy based on OLB

\begin{tabular}{lll}
\hline Authors & Diagnosis (\%) & Change in Therapy (\%) \\
\hline Nelems et al.[5] & 96.0 & Undetermined \\
Warner et al.[40] & 66.0 & 70.0 \\
Wagner et al.[2] & 56.0 & 78.0 \\
Canver et al.[46] & 100.0 & 67.0 \\
Lachapelle et al.[44] & 68.0 & 59.0 \\
Hughes et al.[47] & 63.0 & 85.0 \\
Papazian et al.[49] & 59.0 & 91.7 \\
Kramer et al.[57] & 85.0 & 46.0 \\
Flabouris et al.[8] & 46.0 & 39.0 \\
Chuang et al.[45] & 47.0 & 65.0 \\
Patel et al.[23] & 60.0 & 60.0 \\
Soh et al.[50] & 53.1 & 46.9 \\
Kao et al.[43] & 44.0 & 73.0 \\
Barbas et al.[38] & 100.0 & Undetermined \\
Cho et al.[20] & Undetermined & Undetermined \\
Arabi et al.[39] & 100.0 & 98.0 \\
Lim et al.[4] & 68.0 & 64.0 \\
Papazian et al.[59] & 71.0 & 78.0 \\
Baumann et al.[24] & 70.4 & 81.5 \\
Charbonney et al.[51] & 68.0 & 89.0 \\
Melo et al.[41] & 95.0 & 74.0 \\
\hline & &
\end{tabular}


Table 3. Type of access and method of determination site for OLB

\begin{tabular}{|c|c|c|}
\hline Authors & Type of Access & Method \\
\hline Nelems et al.[5] & Limited thoracotomy & Bx determined by radiology findings \\
\hline Warner et al.[40] & Limited thoracotomy & Bx from the most involved site \\
\hline Wagner et al.[2] & Limited antero-lateral thoracotomy & Multiple wedges from involved area \\
\hline Canver et al.[46] & Thoracotomy & $\mathrm{N} / \mathrm{A}$ \\
\hline Lachapelle et al.[44] & Limited anterior thoracotomy & $\begin{array}{l}\text { Multiple Bx (two wedges from two lobes excluding lingual \& } \\
\text { including normal \& abnormal lung) }\end{array}$ \\
\hline Hughes et al.[47] & Thoracotomy & $\mathrm{N} / \mathrm{A}$ \\
\hline Papazian et al.[49] & Lateral thoracotomy & Bx from the most involved site \\
\hline Kramer et al.[57] & Short anterior thoracotomy at the $3^{\text {rd }}$ intercostals space & $\begin{array}{l}\text { Bx site determined upon radiology results from one or two } \\
\text { lobes }\end{array}$ \\
\hline Flabouris et al.[8] & Anterior mini-thoracotomy & Bx site based on radiology \pm lingula \\
\hline Chuang et al.[45] & Limited thoracotomy & Bx from site of infiltration \\
\hline Patel et al.[23] & Thoracotomy/thoracoscopy & $\mathrm{N} / \mathrm{A}$ \\
\hline Soh et al.[50] & Limited anterior thoracotomy/VATS & $\mathrm{N} / \mathrm{A}$ \\
\hline Kao et al.[43] & $\mathrm{N} / \mathrm{A}$ & Bx site new and progressive lesion identified by CT or CXR \\
\hline Barbas et al.[38] & Limited thoracotomy & Two samples taken \\
\hline Cho et al.[20] & $\begin{array}{l}\text { Standard anterolateral/lateral muscle. sparing } \\
\text { thoracotomy/thoracoscopy }\end{array}$ & Bx taken from two different areas \\
\hline Arabi et al.[39] & N/A & $\mathrm{N} / \mathrm{A}$ \\
\hline Lim et al.[4] & VATS/Anterior mini-thoracotomy & Multiple wedge Bx based on radiology findings \\
\hline Papazian et al.[59] & Lateral thoracotomy & Bx from most involved site \\
\hline Baumann et al.[24] & Antero-lateral mini-thoracotomy & Bx site based on radiology \& intraoperative findings \\
\hline Charbonney et al.[51] & Axillary-anterior incision & Bx from tip of lingula \\
\hline Melo et al.[41] & Thoracotomy & Bx site based on radiology findings \\
\hline
\end{tabular}

$\mathrm{Bx}=$ Biopsy, VATS = Video-assisted thoracoscopic surgery, $\mathrm{N} / \mathrm{A}=$ Not applicable, $\mathrm{CXR}=$ Chest X-ray

or disease ${ }^{[29]}$.

The value of Trans-bronchial Needel Biopsy (TBB) is well-established in the diagnosis of pulmonary infiltrates in spontaneously breathing patients ${ }^{[30]}$. TBB can be performed with acceptable risk in patients on a mechanical ventilator; the risk of pneumothorax can reach up to $19 \%$ in ARDS patients ${ }^{[31-35]}$. The main drawback of TBB is the small size of the specimens, which limits their use for further microbiologic studies. When BAL and TBB fail to provide diagnosis in patients with respiratory failure, the clinician must weigh the risk of empiric therapy against that of OLB ${ }^{[24]}$.

\section{OLB AND SPECIFIC DIAGNOSES}

A complete history, thorough physical examination, radiologic studies, sputum cytologic analysis, and cultures can provide a reliable diagnosis in approximately $30 \%$ of patients ${ }^{[36]}$. However, OLB has been found to have a higher specific diagnostic yield, reaching up to $100 \%{ }^{[37-39]}$. In reviewing the literature, it was found that many authors documented that OLB is useful and safe. Moreover, it can provide a diagnosis that was not previously suspected. This could be of utmost value in the instillation of a new therapy or changing a previously established therapy ${ }^{[23]}$. Table 2 shows the percentages of specific histological diagnoses obtained after OLB in different studies. In the majority of these studies, more than $50 \%$ of patients received a specific diagnosis. Moreover, the specific diagnostic yield was $100 \%$ in the studies conducted by Arabi et al. ${ }^{\left[{ }^{39]}\right.}$ and Barbaras et al. ${ }^{[38]}$. Specific diagnosis could consequently alter the treatment plans and therapy in these patients and hence their outcome. These alterations can include changes in drugs, such as antibiotics and/or corticosteroids. Changes can also include heparinization and the initiation and/or discontinuation of antineoplastic drugs ${ }^{[40]}$. In a study by Baumann et al. ${ }^{[24]}$, two patients were considered for lung transplantation based on the results of the OLB.

In the 22 studies reviewed, it was found that the specific diagnostic yield following OLB ranged from $44 \%$ to $100 \%$. It is difficult to explain this variation in the specific diagnostic yield between different studies. However, it could be related to the size of the sample. Moreover, it could be explained by the variation in classification of the specific diagnosis among the studies. Melo et al. ${ }^{[41]}$ stated that the ideal size of the specimen should measure at least 3 $\mathrm{cm}$ from the largest point and should be obtained from more than one lobe ${ }^{[41,42]}$. Thoracotomy is preferred over video-assisted thoracoscopic biopsy as it is swifter and there is no need to replace the orotracheal tube with a double lumen tube or any need for selective lung ventilation ${ }^{[41]}$. Furthermore, OLB could be performed in either the operating room or bedside in the ICU by an experienced thoracic surgeon. Kao et al. ${ }^{[43]}$ recommended bedside OLB 
Table 4. List of complications that were encountered with OLB

\begin{tabular}{|c|c|c|c|}
\hline Complication & & Study \& Percentages & \\
\hline Hemothorax \& Bleeding & $\begin{array}{l}\text {-Baumann et al. [24]; 3.7\% } \\
\text {-Flabouris et al. [8]; 4.2\% } \\
\text {-Nelmes et al. [5]; 3.6\% }\end{array}$ & $\begin{array}{l}\text {-Charbonney et al. [51]; } 10.5 \% \\
\text {-Kramer et al. [57], 1\% } \\
\text {-Warner et al. [40]; } 1.3 \%\end{array}$ & $\begin{array}{l}\text {-Hughes et al. [47]; 3.7\% } \\
\text {-Papazian et al.1998 [49]; } 2.7 \% \\
\text {-Patel et al. [23]; 3.5\% }\end{array}$ \\
\hline Infection & -Kramer et al. [57]; 7\% & & \\
\hline Wound infection & -Baumann et al [24]; 7\% & -Soh et al. [50]; 3.1\% & \\
\hline Empyema & -Soh et al. [50]; 3.1\% & -Wagner et al. [2]; 2\% & -Lachapelle et al. [44]; 3.2\% \\
\hline Pneumothorax & $\begin{array}{l}\text {-Baumann et al. [24]; 33\% } \\
\text {-Hughes et al. [47]; } 3.7 \% \\
\text {-Nelmes et al. [5]; } 6.3 \% \\
\text {-Warner et al. [40]; } 70 \%\end{array}$ & $\begin{array}{l}\text {-Canver et al. [46]; 18\% } \\
\text {-Kramer et al. [57]; 7\% } \\
\text {-Papazian et al.1998 [49]; 2.7\% }\end{array}$ & $\begin{array}{l}\text {-Charbonney et al. [51] ; 10.5\% } \\
\text {-Papazian et al. 2007[60]; 2\% } \\
\text {-Wagner et al. [2]; 2\% } \\
\text {-Patel et al. [23]; } 8.8 \%\end{array}$ \\
\hline Persistent air leak & $\begin{array}{l}\text {-Arabi et al. [39] ; 33\% } \\
\text {-Charbonney et al. [51] ; 5.3\% } \\
\text {-Lim et al. [3]; 42\% } \\
\text {-Patel } \text { et al. [23]; 3.8\% } \\
\text { Lachapelle et al. [44]; } 16.1 \%\end{array}$ & $\begin{array}{l}\text {-Baumann et al. [24]; } 11 \% \\
\text {-Cho et al. [20]; } 30.2 \% \\
\text {-Melo et al. [41]; } 21 \% \\
\text {-Soh et al. [50]; } 28.1 \%\end{array}$ & $\begin{array}{l}\text {-Canver et al. [46] ; } 55 \% \\
\text {-Flabouris et al. [8] ; } 17 \% \\
\text {-Nelmes et al. [5]; } 7.1 \% \\
\text {-Hughes et al. [47] ; } 18.5 \%\end{array}$ \\
\hline Subcutaneous emphysema & -Patel et al. [23]; 1.3\% & & \\
\hline Tension pneumothorax & -Nelmes et al. [5]; 7.1\% & & \\
\hline Pneumomediastinum & -Kramer et al. [57]; $1 \%$ & & \\
\hline Bronchopleural fistula & $\begin{array}{l}\text {-Baumann et al. [24]; 3.7\% } \\
\text {-Wagner et al. [2]; 8\% }\end{array}$ & -Soh et al. [50]; 6.3\% & -Barbas et al. [38]; 16.7\% \\
\hline Atelectasis & -Kramer et al. [57]; 2\% & & \\
\hline Pleural collection & -Warner et al. [40]; 1.3\% & & \\
\hline Postoperative progressive hypoxemia & -Canver et al. [46]; 18\% & & \\
\hline Intraoperative hypotension & $\begin{array}{l}\text {-Canver et al. [46]; 9\% } \\
\text { Lim et al. [3] ; 13.9\% }\end{array}$ & -Flabouris et al. [8]; 4.2\% & -Hughes et al. [47] ; 3.7\% \\
\hline Intraoperative desaturation & -Flabouris et al. [8]; 17.7\% & -Hughes et al. [47] ; 3.7\% & \\
\hline Acute renal failure & -Patel et al. [23] ; 10.5\% & & \\
\hline New dialysis & -Patel et al. [23] ; 1.8\% & & \\
\hline Myocardial infarction & -Kao et al. [43]; 2.4\% & -Hughes et al. [47] ; 3.7\% & -Warner et al. [40]; 2.5\% \\
\hline Multi-organ failure & -Chuang et al. [45]; 24\% & -Kao et al. [43]; $24.4 \%$ & \\
\hline Septic Shock & -Kao et al. [43]; 21.9\% & & \\
\hline Hypovolumic shock & -Kao et al. [43]; 2.4\% & & \\
\hline Prolonged Mechanical Ventilation & -Kramer et al. [57]; 8\% & & \\
\hline Ventricular tachycardia & -Lachapelle et al. [44]; 3.2\% & & \\
\hline Cerebral haemorrhage & -Lachapelle et al. [44]; 3.2\% & & \\
\hline Respiratory failure & -Lachapelle et al. [44]; 9.7\% & & \\
\hline Sepsis & -Lachapelle et al. [44]; 16.1\% & & \\
\hline
\end{tabular}

if FiO2 levels reach 1 with an applied positive end-expiratory pressure (PEEP) of at least $12 \mathrm{~cm} \mathrm{H}_{2} \mathrm{O}$. Table 3 shows both the method of access and how the site of OLB was determined in each study.

\section{COMPLICATIONS FOLLOWING OLB}

OLB is an invasive surgical procedure, but it is believed to be safe in patients who are not critically ill. Many authors have studied the outcome of OLB in critically ill patients or those who are supported by mechanical ventilation ${ }^{[8,39,44]}$. However, this procedure can have considerable complications that may result in death ${ }^{[44]}$. The various complications that have been encountered with OLB are listed in Table 4, and their rates are shown in Table 5. In the reviewed studies, complication rates ranged from $0 \%$ to $56 \%$. Arabi et al. ${ }^{[39]}$ reported complications in $0 \%$ of cases, which can be explained by the retrospective nature of this study. Also, minor complication may have been encountered but not mentioned, as this study only considered major complications. Melo et al. ${ }^{[41]}$ experienced a high percentage of complications that can be explained by the fact that all patients in this study were under mechanical ventilator support with high PEEP, which predisposes patients to prolonged air leakage. In general, the difference in complication rates between studies could be attributed to differences in patient populations and in the various definitions of complications. The most common reported complication in ventilated patients who underwent OLB was persistent air leak ${ }^{[8,}$ 
Table 5. Incidence of complications in the studies

\begin{tabular}{ll}
\hline Authors & Complications (\%) \\
\hline Nelems et al.[5] & 17.9 \\
Warner et al.[40] & 19.0 \\
Wagner et al.[2] & 14.0 \\
Canver et al.[46] & 40.0 \\
Lachapelle et al.[44] & 19.0 \\
Hughes et al.[47] & 37.0 \\
Papazian et al.[49] & 8.0 \\
Kramer et al.[57] & 25.0 \\
Flabouris et al.[8] & 17.0 \\
Chuang et al.[45] & 24.0 \\
Patel et al.[23] & 39.0 \\
Soh et al.[50] & 40.6 \\
Kao et al.[43] & 20.0 \\
Barbas et al.[38] & 16.7 \\
Cho et al.[20] & 30.2 \\
Arabi et al.[39] & 0.0 \\
Lim et al.[4] & 56.0 \\
Papazian et al.[59] & 10.0 \\
Baumann et al.[24] & 52.0 \\
Charbonney et al.[51] & 25.0 \\
Melo et al.[41] & 21.0 \\
\hline
\end{tabular}

23, 45-49]. The incidence of persistent air leak following OLB reached up to $42 \%$. Peak airway pressure (Ppeak) was the only documented factor to predict persistent air leak after OLB. Persistent air leak was found to be reduced by $42 \%$ for each $5 \mathrm{~cm} \mathrm{H} 20$ reduction in Ppeak ${ }^{[41]}$. Other reported complications included bleeding ${ }^{[8,}$ 23, 46-48], pneumothorax [8, 46, 47, 49], myocardial infarction [47], intraoperative cardiac arrest [23], acute renal failure ${ }^{[23]}$, hypotension ${ }^{[46,47]}$, bronchopleural fistula, empyema, wound infection ${ }^{[50]}$, and respiratory deterioration ${ }^{[46-48]}$.

\section{MORTALITY AND SURVIVAL AFTER OLB}

Mortality rates ranged between $11.3 \%$ and $89.0 \%$. The high mortality rate of $89.0 \%$ was reported by Charbonney et al. ${ }^{[51]}$, who did not attribute this to the OLB procedure but rather to the multiple associated organ disorders in those patients and the severity of their organ damage. Many of the studies had a low associated mortality rate, even in patients on mechanical ventila-

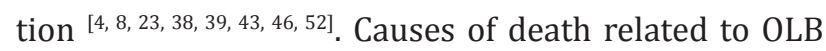
included cardiac arrest ${ }^{[23]}$, hemorrhage, and tension pneumothorax ${ }^{[8]}$.

Some of the studies attributed the deaths to the primary disease or multiple organ failure ${ }^{[39,41,51]}$. In fact, it is difficult to attribute the death of a critically ill patient who may be on mechanical ventilation or have multi-organ failure to a single cause. Death in this category of patients is always multi-factorial. While OLB can be ruled out as directly causing death in critically ill patients, it cannot be excluded as playing an indirect role in these
Table 6. Survival and mortality following OLB

\begin{tabular}{ll}
\hline Authors & Mortality (\%) \\
\hline Nelems et al.[5] & 57.0 \\
Warner et al.[40] & 70.0 \\
Wagner et al.[2] & 14.0 \\
Canver et al.[46] & 51.9 \\
Lachapelle et al.[44] & 58.1 \\
Hughes et al.[47] & 63.0 \\
Papazian et al.[49] & 50.0 \\
Kramer et al.[57] & 20.0 \\
Flabouris et al.[8] & 67.0 \\
Chuang et al.[45] & 59.0 \\
Patel et al.[23] & 53.0 \\
Soh et al.[50] & 57.0 \\
Kao et al.[43] & 51.0 \\
Barbas et al.[38] & 50.0 \\
Cho et al.[20] & 11.3 \\
Arabi et al.[39] & 57.0 \\
Lim et al.[4] & 50.0 \\
Papazian et al.[59] & 59.5 \\
Baumann et al.[24] & 48.2 \\
Charbonney et al.[51] & 89.0 \\
Melo et al.[41] & 47.0 \\
\hline
\end{tabular}

deaths. Table 6 provides the mortality and survival rates following OLB that were documented in the reviewed studies.

\section{EFFECT OF OLB ON TREATMENT PLAN}

OLB can potentially result in a specific diagnosis in up to $100 \%$ of patients ${ }^{[39]}$. Table 2 shows the rate of specific diagnosis and changes in therapy in the reviewed studies based on OLB results.

Therapy alteration following OLB ranged up to $75 \%{ }^{[8,}$ ${ }^{39]}$. The high percentage of therapeutic changes that were made based on the results of biopsy procedures suggests that lung biopsy provides information that is useful to clinicians in decision making and hence in improving patient outcome. Wagner et al. ${ }^{[2]}$ stated uncertainty as to whether the information provided by OLB is sufficiently beneficial to justify its routine use. While some of the previous studies showed improved survival in patients for whom biopsy established a specific diagnosis ${ }^{[53,54]}$, another failed to demonstrate any difference in mortality

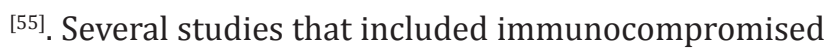
patients showed only a modest impact of OLB on clinical course and no difference in long-term survival [10,11, 56, 57]. Although Potter et al. ${ }^{[58]}$ stated that OLB-directed therapy may offer no advantage over empiric therapy directed at the most likely pathogens, Charbonney et al. ${ }^{[51]}$ and Papazian et al. ${ }^{[59]}$ found that OLB helped doctors to avoid further futile care in patients with terminal illness. In summary, OLB is of value in establishing a solid diagnosis and hence a clear plan of treatment. While there 


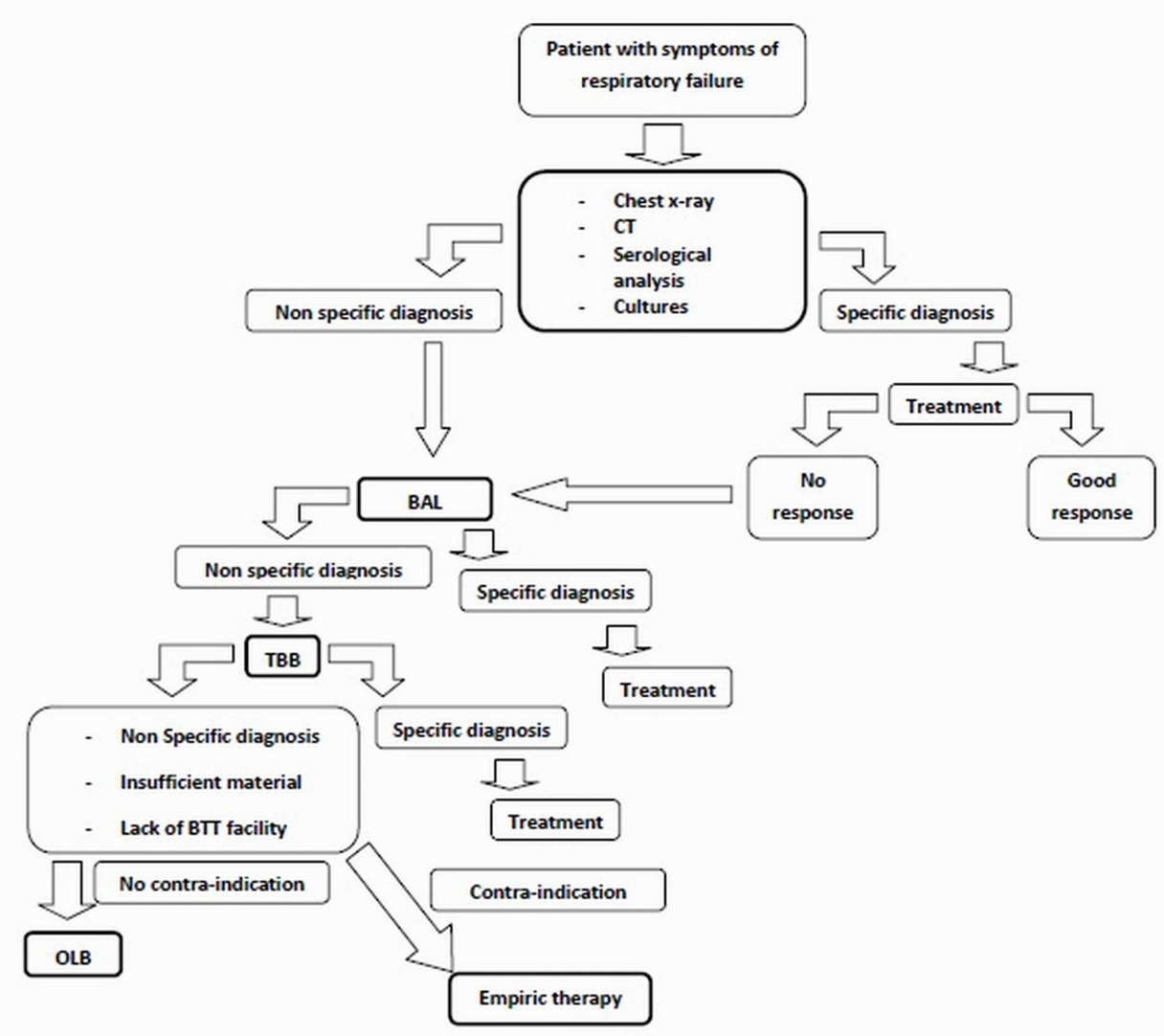

Figure 1. Algorithm for diagnosing patients with diffuse lung diseases and respiratory failure.

are some related complications, the most common complications have no or minor effects on outcome. Based on the literature review, we created a probable algorithm (Figure 1) that could be of value for determining if OLB should be used as a last choice to reach a diagnosis in critically ill patients after BAL and BTT trials. It should be noted that delay in diagnosis should be avoided, and these steps should be conducted in rapid sequence in order to reach a correct diagnosis and then to establish a proper treatment plan.

\section{Conclusion}

In conclusion, OLB is a potentially safe procedure that could help to establish a diagnosis in patients with diffuse lung disease and respiratory failure. It may lead to significant changes in therapy. Until now, the clinical or biomedical parameters that could predict those at high risk for complications following OLB were unknown. Further randomized clinical trials could be useful to clarify the benefits and drawbacks of OLB in critically ill patients.

\section{DECLARATIONS}

Authors' contributions

All authors have contributed equally in the manuscript.

Conflicts of interest

All authors declare that they are bound by confidentiality agreements that prevent them from disclosing their conflicts of interest in this work.

\section{REFERENCES}

1. Krell, W. S. (1988). Pulmonary diagnostic procedures in the critically ill. Critical care clinics, 4(2), 393-407.

2. Wagner, J. D., Stahler, C., Knox, S., Brinton, M., \& Knecht, B. (1992). Clinical utility of open lung biopsy for undiagnosed pulmonary infiltrates. The American journal of surgery, 164(2), 104-107.

3. Walker, W. A., Cole Jr, F. H., Khandekar, A., Mahfood, S. S., \& Watson, D. C. (1989). Does open lung biopsy affect treatment in patients with diffuse pulmonary infiltrates?. The Journal of thoracic and cardiovascular surgery, 97(4), 534-540. 
4. Lim, S. Y., Suh, G. Y., Choi, J. C., Koh, W. J., Lim, S. Y., Han, J., ... \& Kwon, O. J. (2007). Usefulness of open lung biopsy in mechanically ventilated patients with undiagnosed diffuse pulmonary infiltrates: influence of comorbidities and organ dysfunction. Critical care, 11(4), R93.

5. Nelems, J. M., Cooper, J. D., Henderson, R. D., Peng, T., \& Phillips, M. J. (1976). Emergency open lung biopsy. The Annals of thoracic surgery, 22(3), 260-264.

6. Bove, P., Ranger,W., Pursel, S., Glover,J., Bove, K., \& Bendick, P. (1994). Evaluation of outcome following open lung biopsy. The American surgeon, 60(8), 564-570.

7. Gaensler, E. A., \& Carrington, C. B. (1980). Open biopsy for chronic diffuse infiltrative lung disease: clinical, roentgenographic, and physiological correlations in 502 patients. The Annals of thoracic surgery, 30(5), 411-426.

8. Flabouris, A., \& Myburgh, J. (1999). The utility of open lung biopsy in patients requiring mechanical ventilation. Chest, 115(3), 811-817.

9. Utz, J. P., Perrella, M. A., \& Rd, R. E. (1991). Lung biopsy. Adv Intern Med, 37, 337-361.

10. Hiatt, J. R., Gong, H., Mulder, D. G., \& Ramming, K. P. (1982). The value of open lung biopsy in the immunosuppressed patient. Surgery, 92(2), 285-291.

11. Haverkos, H. W., Dowling, J. N., William, A., Myerowitz, R. L., Lerberg, D. B., \& Hakala, T. R. (1983). Diagnosis of pneumonitis in immunocompromised patients by open lung biopsy. Cancer, 52(6), 1093-1097.

12. Prober, C. G., Whyte, H., \& Smith, C. R. (1984). Open lung biopsy in immunocompromised children with pulmonary infiltrates. American Journal of Diseases of Children, 138(1), 60-63.

13. Thomas, J. H., Farek, P. E., Hermreck, A. S., \& Pierce, G. E. (1987). Diagnostic value of open lung biopsy in immunocompromised patients. The American journal of surgery, 154(6), 692-695.

14. Snyder, C. L., Ramsay, N. K., McGlave, P. B., Ferrell, K. L., \& Leonard, A. S. (1990). Diagnostic open-lung biopsy after bone marrow transplantation. Journal of pediatric surgery, 25(8), 871-877.

15. Early, G. L., Williams, T. E., \& Kilman, J. W. (1985). Open lung biopsy: its effects on therapy in the pediatric patient. Chest, 87(4), 467-469.

16. Doolin, E. J., Luck, S. R., Sherman, J. O., \& Raffensperger, J. G. (1986). Emergency lung biopsy: Friend or foe of the immunosuppressed child?. Journal of pediatric surgery, 21(6), 485-487.

17. Malhotra, A., \& Patel, S. (2006). Lung biopsy in ARDS: is it worth the risk?. Critical Care, 10(4), 160.

18. European, R. S., \& American Thoracic Society. (2002). American Thoracic Society/European Respiratory Society international multidisciplinary consensus classification of the idiopathic interstitial pneumonias. This joint statement of the American Thoracic Society (ATS), and the European Respiratory Society (ERS) was adopted by the ATS board of directors, June 2001 and by theERS executive committee, June 2001. American Journal of Respiratory and Critical Care Medicine, 165(2), 277.

19. Bajwa, E. K., Ayas, N. T., Schulzer, M., Mak, E., Ryu, J. H., \& Malhotra, A. (2005). Interferon- $\gamma 1$ b therapy in idiopathic pulmonary fibrosis: a metaanalysis. Chest, 128(1), 203206.

20. Cho, M. H., Malhotra, A., Donahue, D. M., Wain, J. C., Harris, R. S., Karmpaliotis, D., \& Patel, S. R. (2006). Mechanical ventilation and air leaks after lung biopsy for acute respiratory distress syndrome. The Annals of thoracic surgery, 82(1), 261-266.

21. Meduri, G. U., Headley, A. S., Golden, E., Carson, S. J., Umberger, R. A., Kelso, T., \& Tolley, E. A. (1998). Effect of prolonged methylprednisolone therapy in unresolving acute respiratory distress syndrome: a randomized controlled trial. Jama, 280(2), 159-165.

22. Esteban, A., Fernández-Segoviano, P., Frutos-Vivar, F., Aramburu,J.A., Nájera,L., Ferguson, N.D.,...\&Ríos, F.(2004). Comparison of clinical criteria for the acute respiratory distress syndrome with autopsy findings. Annals of internal medicine, 141(6), 440-445.

23. Patel, S. R., Karmpaliotis, D., Ayas, N. T., Mark, E. J., Wain, J., Thompson, B. T., \& Malhotra, A. (2004). The role of openlung biopsy in ARDS. Chest, 125(1), 197-202.

24. Baumann, H. J., Kluge, S., Balke, L., Yekebas, E., Izbicki, J. R., Amthor, M., ... \& Meyer, A. (2008). Yield and safety of bedside open lung biopsy in mechanically ventilated patients with acute lung injury or acute respiratory distress syndrome. Surgery, 143(3), 426-433.

25. Miller Jr, W. T., Tino, G., \& Friedburg, J. S. (1998). Thoracic CT in the intensive care unit: assessment of clinical usefulness. Radiology, 209(2), 491-498.

26. Mäurer,J., Kendzia, A., Gerlach, H., Pappert, D., Hierholzer,J., Falke,K.J.,\&Felix,R.(1998).Morphologicalchangesinchest radiographs of patients with acute respiratory distress syndrome (ARDS). Intensive care medicine, 24(11), 11521156.

27. Chastre, J., Fagon, J. Y., Bornet-Lecso, M., Calvat, S., Dombret, M. C., al Khani, R. H. A. Y. D. A. H., ... \& Gibert, C. (1995). Evaluation of bronchoscopic techniques for the diagnosis of nosocomial pneumonia. American journal of respiratory and critical care medicine, 152(1), 231-240.

28. Azoulay, E., Cohen, Y., Zahar, J. R., Garrouste-Orgeas, M., Adrie, C., Moine, P., ... \& Timsit, J. F. (2004). Practices in nonneutropenic ICU patients with Candida-positive airway specimens. Intensive care medicine, 30(7), 1384-1389.

29. Tamm, M., Traenkle, P., Solèr, M., Bolliger, C. T., Grilli, B., Dalquen, P., \& Cathomas, G. (2001). Pulmonary cytomegalovirus infection in immunocompromised patients. Chest, 119(3), 838-843.

30. Jain, P., Sandur, S., Meli, Y., Arroliga, A. C., Stoller, J. K., \& Mehta, A. C. (2004). Role of flexible bronchoscopy in immunocompromised patients with lung 
infiltrates. Chest, 125(2), 712-722.

31. O'Brien,J.D.,Ettinger,N.A.,Shevlin, D.,\&Kollef, M.H.(1997). Safety and yield of transbronchial biopsy in mechanically ventilated patients. Critical care medicine, 25(3), 440446.

32. Pincus, P. S., Kallenbach, J. M., Hurwitz, M. D., Clinton, C. O. L. I. N., Feldman, C. H. A. R. L. E. S., Abramowitz, J. A., \& Zwi, S. A. U. L. (1987). Transbronchial biopsy during mechanical ventilation. Critical care medicine, 15(12), 1136-1139.

33. Papin, T. A., Grum, C. M., \& Weg, J. G. (1986). Transbronchial biopsy during mechanical ventilation. Chest, 89(2), 168170.

34. Martin, C., Papazian, L., Payan, M. J., Saux, P., \& Gouin, F. (1995). Pulmonary fibrosis correlates with outcome in adult respiratory distress syndrome: a study in mechanically ventilated patients. Chest, 107(1), 196-200.

35. Bulpa, P. A., Dive, A. M., Mertens, L., Delos, M. A., Jamart, J., Evrard, P. A., \& Gonzalez, M. R. (2003). Combined bronchoalveolar lavage and transbronchial lung biopsy: safety and yield in ventilated patients. European Respiratory Journal, 21(3), 489-494.

36. Gaensler, E. A., \& Carrington, C. B. (1980). Open biopsy for chronic diffuse infiltrative lung disease: clinical, roentgenographic, and physiological correlations in 502 patients. The Annals of thoracic surgery, 30(5), 411-426.

37. Cheson, B. D., Samlowski, W. E., Tang, T. T., \& Spruance, S. L. (1985). Value of open-lung biopsy in 87 immunocompromised patients with pulmonary infiltrates. Cancer, 55(2), 453-459.

38. Barbas, C. S. V., Capelozzi, V. L., Hoelz, C., Magaldi, R. B., Souza, R. D., Sandeville, M. L., ... \& Knobel, E. (2006). Impact of open lung biopsy on refractory acute respiratory failure. Jornal Brasileiro de Pneumologia, 32(5), 418-423.

39. Arabi, Y., Ahmed, R., Ahmed, Q., Rahman, M. U., \& Yamani, N. (2007). Risks and benefits of open-lung biopsy in the mechanically ventilated critically ill population: a cohort study and literature review. Medical Science Monitor, 13(8), CR365-CR371.

40. Warner, D. O., Warner, M. A., \& Divertie, M. B. (1988). Open lung biopsy in patients with diffuse pulmonary infiltrates and acute respiratory failure. American Review of Respiratory Disease, 137(1), 90-94.

41. Melo, N., Figueiredo, S., Morais, A., Moura, C. S., Pinho, P., Bastos, P., \& Oliveira, T. (2009). Open lung biopsy in patients on mechanical ventilation with suspected diffuse lung disease. Revista Portuguesa de Pneumologia (English Edition), 15(4), 597-611.

42. Flint, A., Martinez, F. J., Young, M. L., Whyte, R. I., Toews, G. B., \& Lynch III, J. P. (1995). Influence of sample number and biopsy site on the histologic diagnosis of diffuse lung disease. The Annals of thoracic surgery, 60(6), 1605-1608.

43. Kao, K. C., Tsai, Y. H., Wu, Y. K., Chen, N. H., Hsieh, M. J., Huang, S. F., \& Huang, C. C. (2006). Open lung biopsy in early-stage acute respiratory distress syndrome. Critical
Care, 10(4), R106.

44. Lachapelle KJ, Morin JE. Benefit of open lung biopsy in patients with respiratory failure. Can J Surg. 1995; 38(4):316-321.

45. Chuang, M. L., Lin, I. F., Tsai, Y. H., Vintch, J. R., \& Pang, L. C. (2003). The utility of open lung biopsy in patients with diffuse pulmonary infiltrates as related to respiratory distress, its impact on decision making by urgent intervention, and the diagnostic accuracy based on the biopsy location. Journal of intensive care medicine, 18(1), 21-28.

46. Canver, C. C., \& Mentzer, J. R. (1994). The role of open lung biopsy in early and late survival of ventilator-dependent patients with diffuse idiopathic lung disease. The Journal of cardiovascular surgery, 35(2), 151-155.

47. Hughes, R., \& McGuire, G. (1997). Evaluation of open lung biopsy in critically ill, ventilator dependent intensive care unit patients. Canadian Respiratory Journal, 4(5), 246-250.

48. Kornecki, A., \& Shemie, S. D. (2001). Open lung biopsy in children with respiratory failure. Critical care medicine, 29(6), 1247-1250.

49. Papazian, L., Thomas, P., Bregeon, F., Garbe, L., Zandotti, C., Saux, P., ... \& Gouin, F. (1998). Open-lung biopsy in patients with acute respiratory distress syndrome. Anesthesiology: The Journal of the American Society of Anesthesiologists, 88(4), 935-944.

50. Soh, L. H., Chian, C. F., Su, W. L., Yan, H. C., Perng, W. C., \& Wu, C.P.(2005).Roleofopenlung biopsyin patients with diffuse lung infiltrates and acute respiratory failure. Journal of the Formosan Medical Association, 104(1), 17-21.

51. Charbonney, E., Robert, J., Pache, J. C., Chevrolet, J. C., \& Eggimann, P. (2009). Impact of bedside open lung biopsies on the management of mechanically ventilated immunocompromised patients with acute respiratory distress syndrome of unknown etiology. Journal of critical care, 24(1), 122-128.

52. Monteiro, A. S., Addor, G., Nigri, D. H., \& Franco, C. A. D. B. (2005). Open lung biopsy in patients on mechanical ventilation and presenting diffuse pulmonary infiltrate. Jornal Brasileiro de Pneumologia, 31(3), 212218.

53. Greenman, R. L., Goodall, P. T., \& King, D. (1975). Lung biopsy in immunocompromised hosts. The American journal of medicine, 59(4), 488-496.

54. Pennington, J. E., \& Feldman, N. T. (1977). Pulmonary infiltrates and fever in patients with hematologic malignancy: assessment of transbronchial biopsy. The American journal of medicine, 62(4), 581-587.

55. Wharton, J. M., COLEMAN, D. L., WOFSY, C. B., LUCE, J. M., BLUMENFELD, W., HADLEY, W. K., ... \& HOPEWELL, P. C. (1986). Trimethoprim-sulfamethoxazole or pentamidine for Pneumocystis carinii pneumonia in the acquired immunodeficiency syndrome: a prospective randomized 
trial. Annals of internal medicine, 105(1), 37-44.

56. Hall, T. S., Hutchins, G. M., \& Baker, R. R. (1987). A critical review of the use of open lung biopsy in the management of the oncologic patient with acute pulmonary infiltrates. American journal of clinical oncology, 10(3), 249-252.

57. Kramer, M. R., Mintz, B., \& Saute, M. (1998). The role of open lung biopsy in the management and outcome of patients with diffuse lung disease. The Annals of thoracic surgery, 65(1), 198-202.
58. Potter, D., Pass, H. I., Brower, S., Macher, A., Browne, M., Thaler, M., ... \& Pizzo, P. (1985). Prospective randomized study of open lung biopsy versus empirical antibiotic therapy for acute pneumonitis in nonneutropenic cancer patients. The Annals of thoracic surgery, 40(5), 422-428.

59. Papazian, L., Doddoli, C., Chetaille, B., Gernez, Y., Thirion, X., Roch, A., ... \& Thomas, P. (2007). A contributive result of open-lung biopsy improves survival in acute respiratory distress syndrome patients. Critical care medicine, 35(3), 755-762. 